\section{Vaccine Refusals and Regulations}

\section{TO THE EDITOR:}

As of this writing (June 21, 2019), 1,044 cases of measles have been reported in the United States-a dramatic increase over last year's total (372) and the most cases since 1992. ${ }^{1}$ There is obvious concern about the number of cases and their spread across the country. Dr Seehusen's commentary "Time for Family Physicians to Change Strategy Against Vaccine Refusal" exhorted family physicians to advocate for laws enforcing immunization. ${ }^{2}$ However, restricting exemptions from school-entry mandates will not ameliorate the current situation, and may make it worse.

Four states make up the vast majority of current cases: New York (871 cases in Rockland County, Brooklyn, and Queens), California (53), Pennsylvania (5) and Washington (81). ${ }^{1}$ This fact demonstrates two things: (1) the outbreaks, while continuing, are being contained, and (2) a high national measles vaccination rate among children is successful.

In New York state, the vaccination rate for MMR among toddlers is $92.4 \%$ (91.9\% NYC, $93.1 \%$ rest of state); the rate for kindergartners is $97.2 \%$ in the state and $97.8 \%$ for the city. ${ }^{3,4}$ While rates among the ultraorthodox population in which the outbreaks are occurring appear to be lower, it is not clear that vaccine resistance is the only, or primary, reason why. Sources have documented disrupted relationships between this population and public health, due in part to disputes over traditional circumcision practices as well as purposeful cultural isolation. ${ }^{5,6}$ Restricting exemptions to school-entry vaccine mandates may not improve rates of MMR vaccination in a state with already very high rates.

Historically, exemptions provide a "safety valve" that "prevent[s] backlash against the use of law to achieve compliance with vaccine recommendations." Political activity around vaccination and vaccine mandates is growing. Restricting exemptions to school-entry mandates creates a social climate that is threatening to those who are hesitant, providing motivation for more vocal ideological dissent and doing nothing to ameliorate a highly charged political climate within which parents make medical choices for their children.

Additionally, school-entry mandates do not affect children not in school or organized childcare. To determine the most effective, humane, and ethical approach to diminishing susceptibility to measles outbreaks in the United States-outbreaks that are fueled by tens of thousands of cases abroad-we need more context, data, and deliberation about what makes people dissent from vaccination recommendations, as well as more historical, culturally relevant, and scientifically sound understanding of the current situation. We advocate that family physicians continue to engage families in positive conversations about vaccinations without negative perceptions about parents who raise questions and concerns.

doi: 10.22454/FamMed.2019.959213

Mack Thomas Ruffin, IV, MD, MPH

Bernice L. Hausman, PhD

Penn State College of Medicine

Hershey, PA

\section{References}

1. Centers for Disease Control and Prevention. Measles Cases and Outbreaks. https://www.cdc.gov/measles/cases-outbreaks. html. Accessed June 21, 2019.

2. Seehusen DA. Time for family physicians to change strategy against vaccine refusal. Fam Med. 2019;51(6):468-470.

3. Hill HA, Elam-Evans LD, Yankey D, et al. Vaccination coverage among children aged 19-35 months-United States, 2017. MMWR 2018;67(40):1123-1128. https://www.cdc.gov/ mmwr/volumes/67/wr/mm6740a4.htm. Accessed September 3, 2019.

4. Mellerson JL, Maxwell CB, Knighton CL, et al. Vaccination coverage for selected vaccines and exemption rates among children in kindergarten-United States, 2017-18 school year [Table 2]. MMWR 2018;67(40):1115-1122. https://www. cdc.gov/mmwr/volumes/67/wr/mm6740a3.htm\#T2_down. Accessed September 3, 2019.

5. Otterman, S. New York confronts its worst measles outbreak in decades. The New York Times. January 17, 2019. https:// www.nytimes.com/2019/01/17/nyregion/measles-outbreakjews-nyc.html. Accessed June 15, 2019.

6. Tanne, JH. Ultra-Orthodox Jews criticized over circumcision practice. BMJ January 21, 2006;332:137.

7. Colgrove J. Immunity for the people: the challenge of achieving high vaccine coverage in American history. Public Health Rep. 2007;122(2):248-257. 


\section{Strategy to Address Vaccine Refusal Must Include Research, Training, and Advocacy}

\section{TO THE EDITOR:}

Dr Seehusen's call for family physicians to be involved in advocating for states to pass laws mandating childhood vaccinations against diseases seems prudent in the face of the risks posed to public health, and I have no qualm with it. ${ }^{1}$ Indeed, advocacy is increasingly being viewed as a core component of what a family physician must do. However, what merits further attention are the ethical and philosophical underpinnings behind the state compelling parents to vaccinate their children (barring exemptions for genuine medical concern) in order for such a program not to be viewed as unjustifiably paternalistic.

While Seehusen notes examples where individual freedoms have been restricted to protected populations-such as with drunk driving laws-I would find it helpful to also explicate the ethical underpinning of such a notion. In his "harm principle," John Stuart Mill took the position that "The only purpose for which power can be rightfully exercised over any member of a civilized community, against his will, is to prevent harm to others." Mill's harm principle is often cited in public health ethics and public health intervention strategies as justification for policies that interfere with or abrogate individual liberty. ${ }^{3}$ To me, it seems that further parsing this out for family physicians could be helpful in garnering further advocacy to the cause.

Nonetheless, we also need to be cognizant of the challenges that persist-legal, social, and psychological-with mandatory interventions for childhood vaccinations, that Seehusen does not mention. New York City Mayor Bill de Blasio issued an order this spring requiring unvaccinated persons in certain areas of Brooklyn to receive the measles vaccine or face a $\$ 1,000$ fine. ${ }^{4}$ This was challenged in the courts but was ultimately upheld. Yet, the social and psychological dimensions of mandatory vaccination, especially of children, are largely unknown. In West Virginia, though the state has achieved high levels of childhood vaccination, ${ }^{5}$ the law is only for children enrolled in public school. ${ }^{6}$ Logistical problems are also apparent. Were a parent to continue refusal for vaccination of their child, would the child be forcibly vaccinated, or face a significant fine, as in New York City, or simply not allowed to attend public school? Such a practice is not risk-neutral, as emotional harm to both the parent and the child could ensue from being forcibly vaccinated, and/or not being allowed to attend public school, placing the child's education and future at risk. Further, while a physician or nurse may, in theory, believe that all children should be vaccinated, vaccinating a child whose parent is compliant versus one who is adamantly opposed to the vaccination could also produce harm to the provider in the form of moral distress.

While I agree with the general premise of family physicians advocating for solutions to the childhood vaccination crisis, additional work seems to be needed in order to prepare family physicians for this and to ensure that children and providers are not harmed by the practice. Research into the social and psychological dimensions of mandatory vaccinations-from both a provider and patient perspective-seems prudent. This could be analyzed in West Virginia or in a community that has very recently been mandated to receive vaccinations, such as areas of Brooklyn. Furthermore, if mandatory vaccinations are to continue - and family physicians are to be part of the advocacy and vaccination effort-then training on what exactly advocacy may look like, as well as risks that may ensue, is needed. As mentioned, one of the risks of mandatory vaccinations in a patient who is opposed to such vaccinations is that it may produce moral distress in providers, as the provider is aware they are doing something that is counter the wishes of the patient and/or family. The awareness of this potential risk is an essential first step.

Hence, as Seehusen noted, there is enormous opportunity for family physicians to be involved in advocating for mandatory vaccination laws. However, additional research and training should coincide with this call for advocacy.

doi: 10.22454/FamMed.2019.138424

Daniel J. Hurst, PhD

Cahaba-UAB Family Medicine Residency

Centreville, AL

\section{References}

1. Seehusen DA. Time for Family Physicians to Change Strategy Against Vaccine Refusal. Fam Med. 2019;51(6):468-470.

2. Mill JS. On Liberty and Other Essays. Gray J, ed. 2nd ed New York: Oxford University Press; 1998. 
3. Faden R, Shebaya S. "Public Health Ethics" in: The Stanford Encyclopedia of Philosophy. Winter 2016 ed. Edward N. Zalta ed. https://plato.stanford.edu/archives/win2016/entries/ publichealth-ethics/. Published April 12, 2010. Accessed September 3, 2019.

4. Madani, D. NYC measles vaccination order prevails in court NBC News. April 18, 2019. https://www.nbcnews.com/news/ us-news/challenge-nyc-measles-vaccination-order-dismissedjudge-n996186. Accessed 13 Jul. 2019.

5. Holdren W. West Virginia has highest child vaccination rates in nation, but some parents want more choice. The Register-Herald. March 4, 2018. https://www.register-herald. com/news/west-virginia-has-highest-child-vaccination-ratesin-nation-but/article_c6fb222b-905c-552a-84a3-5bef92763b29. html. Accessed 8 Jun. 2019.

6. West Virginia Code. Chapter 16: Public Health. Article 3: Prevention and Control of Communicable and Other Infectious Diseases. http://www.wvlegislature.gov/wvcode/chapterentire. cfm?chap=16\&art=3\&section=4. Accessed June 8, 2019.

\section{Author's Reply}

\section{TO THE EDITOR:}

Drs Ruffin and Hausmen question whether reducing vaccine exemptions will reduce the risk of measles outbreaks in the future. They reasonably argue that tighter laws around vaccination may have the unfortunate consequence of further alienating a population that already has a high degree of distrust with government health officials. I will, therefore, second their call for further dialogue with communities and individual parents who are hesitant to vaccinate their children in order to try and build trust. This general approach has not resulted in fewer cases of measles over the last two decades. This does not mean we should stop talking. It does mean we need to consider other avenues to protect all children.

Dr Hurst points out the unknown social and psychological impact of forcing a population to receive unwanted vaccinations. He also points out that there may be a cost to providers in the form of moral distress. Both points are valid. There would be consequences to the legislation I have suggested. I believe the positive will outweigh the negative. I greatly appreciate Dr Hurst correctly pointing out that more advocacy training is needed to better equip the next generation of family physicians to deal with future public health issues as well as the potential consequences of the medical interventions that are created to address them.

doi: 10.22454/FamMed.2019.263288

\section{Dean Seehusen, MD, MPH}

Augusta University

Augusta, GA 